Cakrawala Dini: Jurnal Pendidikan Anak Usia Dini | p-ISSN 2087-1317 | e-ISSN 2621-8321 Vol. 12. No.I Mei 2021 | Hal 31-40

\title{
PENGAMATAN TENTANG PEMBELAJARAN DAN PENILAIAN PADA ANAK USIA DINI DI ERA PANDEMI COVID-19
}

\author{
Ani Oktarina ${ }^{1}$, Siti Fatonah ${ }^{2}$ \\ ${ }^{1,2}$ Universitas Islam Negeri Sunan Kalijaga Yogyakarta
}

\begin{abstract}
This research was conducted on the impact of the Covid-19 epidemic and the learning system for teachers and teachers, students and parents. Furthermore, the authors want to see how educators implement the Covid-19 infectious disease grading system. This research methodology uses qualitative case studies to obtain information about learning and assessment in early childhood during the Covid-19 epidemic. Participants in this study are classroom teachers who teach and assess for current Covid-19 pandemic students. The results showed that learning and assessment were performed differently from the previous Covid-19 outbreak, where learning and assessment were conducted in a planned manner and in many other ways online and offline.
\end{abstract}

Keyword: Learning, assessment

\begin{abstract}
Abstrak: Penelitian ini memiliki tujuan untuk mengetahui bagaimana penyebaran wabah Covid-19 mempengaruhi peserta didik, pendidik dan juga wali murid pada system pendidikan, serta tantangan yang ada saat pembelajaran. Selain itu, penulis berharap para guru dapat menggunakan sistem penilaian untuk aktivitas siswa pada saat wabah Covid-19. Metode penelitian menggunakan studi kasus kualitatif untuk memberikan informasi tentang pendidikan anak usia dini dan evaluasi selama epidemi Covid-19. Dukungan yang diperlukan untuk penelitian ini adalah guru kelas yang memberikan bimbingan dan penilaian kepada siswa selama pandemi Covid-19 saat ini. Hasil penelitian menunjukkan bahwa pelatihan dan evaluasi berbeda dengan pelatihan dan evaluasi sebelum wabah Covid-19. Pelatihan dan evaluasi offline dan online dilaksanakan sesuai rencana atau dalam bentuk lain.
\end{abstract}

Kata Kunci: Pembelajaran, penilaian

\footnotetext{
' Universitas Islam Negeri Sunan Kalijaga Yogyakarta, Email: aktarinamuhyins21回gmail.com

2Universitas Islam Negeri Sunan Kalijaga Yogyakarta, Email: siti.fatanah国uin-suka.ac.id
} 


\section{PENDAHULUAN}

Adanya penyebaran wabah yang ada hamper disegala penjuru dunia ternyata berdampak hebat. Ini tidak cuma secara langsung mempengaruhi keuangan, kesehatan dan keselamatan, tetapi juga secara langsung mempengaruhi kegiatan pendidikan. Di Indonesia, semua negara yang tidak terpengaruh Covid-19 telah diabaikan, semua jenjang pendidikan telah mengakhiri pendidikan penuh waktu dan bergeser ke sistem pembelajaran online atau offline (Kementrian Pendidikan dan Kebudayaan Republik Indonesia, 2020). Dampaknya telah terjalin pergantian yang sangat mendadak serta tidak sedikit yang menimbulkan culture shock, baik bagi guru maupun siswa.

Salah satu guncangan budaya berpengaruh pada hambatan belajar, motivasi berprestasi, dan interaksi pembelajaran terbaik dari sistem adaptasi sosial (Agustin, 2011), (Ernofalina, 2017), (Pramudiana \& Setyorini, 2019). Pada saat yang sama, kegiatan pendidikan tambahan mengacu pada kegiatan yang menciptakan lingkungan interaktif yang menarik, mendorong anak untuk bereksperimen, melakukan percakapan tanpa batas dan memiliki banyak kesempatan untuk menggali potensi mereka. (Agustin, M., Djoehaeni, H., \& Dwi Puspita, 2020).

Selain itu, pembelajaran yang efektif membantu anak mendapatkan pengalaman yang menarik dan bermakna, yang akan mereka ingat seiring berjalannya waktu, karena pembelajaran yang baik pada dasarnya merupakan pengalaman yang menyenangkan, kreatif dan bermanfaat bagi anak (Oktarina \& Maemonah, 2019). Konstruktif, tujuan akhirnya adalah membesarkan anak. Selesaikan masalah masa depan. Pada saat wabah Covid-19 menjadi sulit untuk mengadopsi metode pembelajaran suportif ini karena guru sebagai mata pelajaran utama menghadapi tantangan, dan banyak kendala dalam proses penciptaan, kondisi pembelajaran, pembelajaran aktif, dan pengajaran yang berbeda dengan yang digunakan oleh guru. Strategi, metode dan material tidak dapat dipisahkan (Panjaitan, Yetti, \& Nurani, 2020).

Pembelajaran aktif didasarkan pada pengalaman dan praktik yang dimiliki dan dimiliki guru, untuk mengambil tindakan untuk menunjukkan tingkat profesionalitas, jika dibatasi akan sulit untuk meningkatkan kualitas pengajaran, terutama dengan tidak adanya unsur pengajaran interaktif. Dalam proses mengajar (Gore et al., 2017), (Ronkainen, Kuusisto, \& Tirri, 2019). Pengajaran yang bermutu tinggi akan sulit dicapai terutama dalam kegiatan PAUD di PAUD, karena pengajarannya dituntut agar terjaga kedekatannya secara fisik dan mental, karena suasana PAUD lebih bersifat informal dan datang melalui kegiatan daripada kegiatan. Mencermin kan. Tujuannya adalah untuk mencapai prestasi akademik, namun untuk mengoptimal kan perkembangan agar pendidik bisa membuat lingkungan belajar yang ternyaman dan pastinya aman untuk anak (Maiza \& Nurhafizah, 2019). Karena tak bisa disangkal lagi bahwasanya peran dari dalam mengajar sangat penting untuk mencapai pengajaran yang berkualitas dan efektif, bahkan penting secara strategis (Oktarina, Angraini, \& Susilawati, 2020). Mengenai metode pengajaran yang baik ini, berinteraksi dengan anak-anak, meningkat kan hubungan antara guru dan siswa, membangun semacam demokrasi, ada berbagai jenis guru teknologi pengajaran. Bahan ajar yang sesuai dan tepat untuk tumbuh kembang anak dan lingkungan nya. Aman dan nyaman, didukung oleh tenaga profesional yang berperan aktif dalam pendidikan siswa yang berkualitas (Yusuf, 2017). Dalam melaksanakan pengajaran yang efektif, guru yang peran utamanya mengajar adalah guru juga harus jadi pendidik efektif yang memanfa atkan waktunya dalam sebagai pengajar 
secara menyeluruh, menyajikan materi dengan cara yang berbeda, memantau kuri kulum, dan membuat kemajuan melalui evaluasi siswa (Oktarina, 2020). Memberikan kesempatan belajar bagi siswa. Gunakan pengalaman belajar yang khas dari kesediaan menjadi guru muda untuk mencegah pengajaran selama pandemi Covid 19 dan konsekuensi dari pengulang an materi pembelajaran ketika anak-anak tidak mengerti, dan tetapkan tujuan pembelajaran untuk setiap anak. (Setyosari, 2017).

Selain sulitnya menggunakan Covid 19 untuk menciptakan suasana belajar yang efektif, juga terjadi komunikasi dalam kegiatan belajar anak, bukan hanya karena jarak antara guru dengan anak. Dalam hal interaksi online, guru dan anak tidak dapat melakukan pendidikan yang dapat mencapai komunikasi yang optimal. Dalam kegiatan belajar pribadi khususnya dalam kegiatan pembelajaran PAUD memegang peranan yang sangat penting dalam keberhasilan pendidikan peserta didik (Nicoleta, D, 2010), (Khan, Khan, Zia-Ul-Islam, \& Khan, 2017). Aktivitas pribadi akan membersihkan jendela psikologis, mening katkan pengendalian diri, menstabilkan emosi, dan menjaga kesehatan fisik, mental, dan bahkan mental anak. Jadi prihal ini guru paham dan memakai tekhnologi tersebut (Rohita, 2020) Aplikasi dalam pendidikan online secara khusus memenuhi kebutuhan Covid-19. Oleh karena itu, menurut hasil penelitian, sesi pembelajaran termasuk pelatihan pribadi oleh guru dan siswa memberikan motivasi yang lebih besar kepada anak untuk belajar, mengurangi kecemasan dan stress serta membangun kepercayaan diri (Purwanto, 2020) Dalam pembelajaran online, anak-anak lemah dalam menyerap materi yang diajarkan guru, tidak bisa berkomunikasi dan main dengan kawan, sehingga mudah stres.

Kesulitan yang didapat oleh guru PAUD terkait pengajaran selama berlangsungnya penyebaran Covid-19, harus ditangani dengan hati-hati, dan penelitian harus dilakukan dalam bentuk penelitian ilmiah guna mendapatkan data yang andal, andal, dan bertanggung jawab. Selain itu, era pembelajaran baru yang normal akan dimulai dalam jangka pendek yang membutuhkan ketelitian, penerapan prosedur yang ketat, bahkan kehati-hatian dalam penggunaannya, karena kegiatan pelatihan akan dilakukan selama pandemi. Berdasarkan beberapa tema di atas, penelitian ini bertujuan untuk mengevaluasi kendala umum yang dihadapi pendidik usia dini saat mengajarkan wabah Covid-19 dan dampaknya terhadap pembelajaran di era normal baru. Tujuan penelitian ini adalah untuk mengetahui pelatihan dan evaluasi kegiatan selama pandemi Covid-19.

\section{METODOLOGI PENELITIAN}

Penelitian ini memakai studi kasus kualitatif agar mengetahui bagaimana Covid-19 mempengaruhi pembelajaran. Dalam penelitian ini kedalaman interpretasi digunakan sebagai dasar ukuran sampel. Hal ini sesuai dengan pernyataan (Purwanto, 2020) masalahnya bukan pada jumlah sampel, tetapi kekayaan dan kedalaman informasi.

Subjek atau yang akan menjadi responden pada penelitian ini yakni seorang pendidik/guru kelas menengah di Taman Kanak-Kanak Sejahtera Dasar dan merupakan perwakilan dari responden. Penelitian ini didasarkan pada wawancara dan dokumen yang diterima dari sekolah.

Aturan wawancara didasarkan pada aturan wawancara online. Bahkan secara onliine, penulis akan melakukan penelitian ekstensif. Penelitian ini merupa kan studi kasus, dengan menggunakan metode pengambilan sampel sebagai tujuan penelitian tertentu. Bernard mengatakan bahwa melalui pengambilan sampel yang disengaja, tiidak terbatas pengambilan sampel untuk mendapat info yang diperlukan (Syah, 2020). Analisis informasi yang dipakai adalah analisis informasi tematik, sebab pendekatan 
tematik menolong analisis mendalam buat menanggapi pertanyaan.

\section{HASIL PENELITIAN DAN PEMBAHASAN}

Pendidikan Anak Usia Dini meng acu pada pemberian binaan anak sejak awal kelahiran sampai berusia 6 tahun dalam bentuk imbalan pendidikan yang merangsang pertumbuhan fisik dan intelektual. Dipendidikan tinggi (Mendikbud, 2014).

Pembelajaran me rupakan suatu proses interaksi antara guru dan anak, menggunakan berbagai sumber belajar untuk bermain di lingkungan yang aman dan menyenangkan (Mendikbud, 2014).

Bredekamp dan Kopple percaya bahwa pendidikan pra-sekolah mencakup banyak program untuk anak sejak kelahiran umur 8 hingga usia delapan tahun, yang bertujuan peningkatan perke mbangan intelek, social, emosional, bahasa, dan fisic mereka. Dalam situasi inilah berbagai program pendidikan prasekolah dengan berbagai bentuk perkembangan dilaksanakan (Zalyana, 2016).

Proses dari pembelajaran anak usia dini yakni berinteraksi dengan anak, orang tua, atau orang yang lebih dewasa lainnya di lingkungannya untuk mengatasi suatu tantangan. Interaksi struktural merupakan faktor yang mempengaruhi terwujudnya tujuan pembelajaran.

Peristiwa ini terjadi karena interaksi tersebut mencerminkan pengala man yang bermakna dalam komunikasi dan proses pembelajaran antar anak. Vygotsky percaya bahwa pengalaman fisik dari interaksi sosial sangat penting untuk perkembangan proses berpikir anak. Sebagian besar aktivitas intelektual dengan anak-anak dapat dicapai dengan berinteraksi dengan orang lain. (Sisca, 2007) menjelaskan, anak bisa belajar dan bemain dilingungannya sendiri, bermain dan hidup di lingkungannya sendiri, maka pembelajaran itu efektif.
Pendidikan anak usia dini tidak berarti bahwa anak-anak harus dikirim ke sekolah pada usia yang salah dan dipaksa untuk menghadiri kelas, yang pada giliran nya membuat anak- mengambil tugastugas perkembangan. Secara fundamental, pendidkan anak usia dini adalah pendidi kan yang diberikan kepada anak untuk mendorong tumbuh kembangnya.

Setiap kegiatan pembelajaran memiliki tujuan yang ingin dicapai. Untuk mengukur pencapaian tujuan dalam kegiatan pendidikan diperlukan informasi yang berkaitan dengan proses dan hasil kegiatan pendidikan, informasi tersebut dapat berupa data evaluasi. Informasi evaluasi dapat diperoleh melalui berbagai metode, antara lain tes standar dan observasi langsung terhadap anak, baik secara individu maupun kolektif. Evaluasi menggambarkan sebagai proses menentu kan individu atau perilaku individu melalui observasi atau pengujian, kemudian memberikan nilai dalam bentuk angka, skor atau skala (Mukaromah, 2019).

Evaluasi pendidikan merupakan sarana bagi guru supaya bisa tingkatkan lagi kualitas belajar anak dikelas. Namun, memasukkan penilaian ke dalam kurikulum akademis biasanya hanya formalisme, hanya mengikuti aturan tata kelola perusahaan atau menanggapi keingintahuan orang tua tentang pertumbuhan anak mereka. (Wahyudin, 2010). Maka, sangat penting bagi guru untuk mencoba memahami detail penilaian untuk mencapai tujuan pendidikan yang realistis.

Mengingat semakin parahnya fenomena tersebut, artikel ini bertujuan untuk membantu para pendidik prasekolah melakukan kegiatan asesmen tumbuh kembang anak dengan benar, akurat dan bertanggung jawab. Menurut Mulyasa, evaluasi mengacu pada Menggunakan evaluasi, implementasi berkelanjutan, prinsip yang andal, akurat dan konsisten untuk mengumpulkan, menampilkan dan memproses informasi 
tentang hasil belajar anak (Mulyasa, 2012).

Bagi guru, memberi umpan nalik tentang yang dibutuhkan ialah untuk meningkatkan proses pembljaran Penilai an penting bagi pendidik karena memberi kan umpan balik tentang apa yang dibutuh kan untuk meningkatkan proses pembelaj aran (Wahyudin, 2010). Dan lagi, asesmen berguna dipakai sebagai alat untuk mengukur dan mengetahui proses keberhasilan dan hasil pencapaian belajar siswa (Nana, 2009). Evaluasi adalah upaya guru untuk menentukan tingkat kursus dan keberhasilan anak dalam memperoleh keterampilan yang diharapkan. Siswa terutama menggunakan evaluasi kursus untuk mengembangkan kursus sehingga mereka dapat menerap kan kursus berikutnya dengan lebih baik. Untuk menilai keberhasilan keterampilan anak, sebaiknya guru menggunakannya sebagai laporan terkait tumbuh kembang anak dan mengawasi perkembangannya, hingga hasilnya lebih ideal.

Jadi, asesmen adalah sebuah proses tafsiran segala informasi caea sistemats, berkala, terus menerus, komprehensif terkait proses dan hasil tumbuh kembang yang dicapai siswa melalui kegiatan pembelajaran, serta menafsirkan informasi tersebut untuk mengambil keputusan.

Adapun tujuan dan fungsi asesmen perkembangan anak usia dini antara lain: (1) Memberikan umpan balik program pembelajaran sehingga dapat diketahui keberhasilan dan kegagalannya. Tindakan akan berlanjut jika berhasil dan akan meningkat jika gagal. Faktanya adalah bahwa guru memberikan lebih banyak aktivitas kepada anak-anak. sesuai dengan minat dan keterampilan yang memungkin kan anak untuk mencapainya secara optimal, (4) mendefinisikan konteks kesulitan belajar anak selama kegiatan pendidikan, (5) memberikan informasi kepada orang tua tentang keberhasilan dan keterampilan yang dipelajari dan tidak dipelajari oleh anaknya, (6) Sebagai informasi bagi pihak lain yang perlu memberikan arahan lebih lanjut (Samatowa, 2019).

Dengan demikian, dapat disimpulkan bahwa tujuan penilaian pendidikan prasekolah yakni agar mendapati umpan balik (feedback) terkait apa yang dilakukan sebagai informasi untuk pelaksanaan kegiatan selanjutnya, untuk mengetahui efektivitas kegiatan yang dilaksanakan, dan sebagai perbaikan program kegiatan selanjutnya.

\section{HASIL PENELITIAN}

Tujuan dari penelitian ini adalah dapak dari Covid-19 terhadap proses pemb elajaran dan penilaian guru dan siswa. Hasil penelitian yang dilakukan di TK Sejahtera Penengahan mengenai pembelaj aran dan penilaian anak dilakukan melalui wawancara dan beberapa dokumentasi. Berikut adalah penjelasan nya.

1. Observasi

Observasi merupakan langkah awal yang menarik perhatian luas, yaitu observasi partisipatif dan observasi praktek klinis sebagai metode independen (Hasanah, 2017). Observes yakni sebuah Teknik dalam pengumpulan data yang dilaukan oleh suatu pengamatan dengan disertai catatan-catatan terhadapfenomena yang diselidiki (Sutrisno, 2000). Dari hasil penelitian di TK Sejahtera Penengahan, bahwasanya observasi belum bisa dilakukan saat pandemi Covid-19 ini. Dikarena kan harus terus menjaga kesehatan, menjaga jarak dan menjauhi kerumunan. Maka dari itu observasi tidak bisa dilakukan langsung dalam penelitian kali ini yang dilakukan di TK Sejahtera Penengahan.

2. Wawancara

Seperti kita ketahui bersama, ini adalah alat evaluasi yang belum teruji yang tidak bisa dilaksanakan secara langsung ataupun tidak melalui wawanca ra, diskusi, dan tanya jawab (Arifin, 2016). Dalam wawancara terstruktur, pewawancara pertama-tama menjawab 
pertanyaan dan topik lain, sedangkan wawancara tidak terstruktur bersifat informal. Subjek bebas mengajukan pertanyaan atau informasi lain tentang opini, sikap, keyakinan, atau informasi subjek lainnya (Paizaluddin, 2016). Berdasarkan wawancara yang dilakukan, beberapa responden memberi kan pernyataan :

Dari hasil wawancara yang dilakukan di TK Sejahtera Penengahan, sistem pembelajaran yang dilakukan pada saat era pandemi Covid-19 ini dilakukan secara daring dan juga luring. Dikarena kan jumlah siswa yang belum terlalu banyak, jadi TK Sejahtera Penengahan mengada kan pembelajaran secara daring dan luring. Daring yang dilakukan seperti pada umumnya, melakukan zoom, mengirim beberapa pembelajaran melalui via whatsapp, dengan mengirimkan gambar, video atau voice note kepada guru kelas. Sedangkan luring yang dilakukan adalah dengan cara mendatangi rumah siswa dengan jadwal yang sudah ditentukan selama sekitar per 1 minggu 2 kali pertemuan. Masing-masing guru bertanggung jawab atas jadwal yang sudah ditetapkan, bahwasanya guru akan mendatangi rumah anak untuk memulai pembelajaran secara terjadwal dan tentunya kesepakatan ini sudah disepakati oleh pihak sekolah dan pihak wali murid dari peserta didik. Selain dari pada pihak sekolah, kesepakatan daring dan luring ini sebelumnya dilakukan juga karena adanya permintaan dari para wali murid yang juga kesusahan untuk mengajari anaknya dirumah, anak juga kurang bersemangat jika tidak bertatap muka langsung dengan gurunya saat belajar, anak juga mudah bosan jika hanya belajar melalui via whatsapp dan lain sebagainya. Jadi, untuk meminimalisir keadaan, pihak sekolah mengadakan adanya daring dan luring dalam system pembelajaran yang akan diterapkan di TK Sejahtera Penengahan ini, karena jumlah siswa dan jarak rumah siswa dengan guru juga memungkin untuk dilakukan.
Selanjutnya dari hasil wawancara yang dilakukan di TK Sejahtera Penengahan mengenai penilaian tersebut saat dikerjakan pada pendidik / pihak sekolah terhadap hasil dari proses belajar anak adalah dengan cara memberikan penilaian mingguan, nilai yang didapat saat pembelajaran daring yaitu berdasarkan video atau gambar yang dikirimkan melalui whatsapp, atau didapat saat jadwal pembelajaran luring. Jadi saat daring, mulanya guru melakukan video call, ataupun zoom dipagi hari untuk menyapa peserta didik, lalu guru memberikan beberapa pembelajaran yang dijelaskan melalui video yang dikirimkan melalu via whatsapp, lalu peserta dapat memulai pembelajaran dengan divideo kan dan hasilnya dapat difoto lalu dikirim oleh guru. Sedangkan, saat jadwal luring dilakukan, guru dapat membawa alat dan bahan yang digunakan untuk memulai pembelajaran ke rumah masing-masing peserta didik dengan gentian menyesuai kan jadwal yang ada. Dari pembelajaran yang dilakukan saat daring dan luring, guru tetap dapat memberikan penilaian hasil dari pembelajaran anak walaupun tidak setiap hari bisa mendampingi proses pembelajar an anak.

\section{Dokumentasi}

Metode dokumentasi diartikan secara harfiah sebagai masalah pribadi yang terkait erat dan harus dijelaskan secara dekat dengan konteks acara (Burhan, 2015). Menurut Sukharsimi Arikunto, dokumen mengacu pada memperoleh informasi tentang catatan, catatan, buku, surat, majalah, tanda tangan, catatan, rapat, agenda dan variabel (Arikunto, 1998). Jadi dapat disimpulkan bahwa metode perdokumen tasian yakni cara yang tepat untuk dilakukan dalam menyediakan data yang dibutuhkn.

Dari hasil penelitian yang dilakukan di TK Sejahtera Penengahan, bawasanya dokumentasi yang dikumpulkan yaitu beberapa foto kegiatan guru dan peserta didik dalam menjalankan aktivitas pembelajaran dan penilaian yang 
dilakukan di era pandemi Covid-19 ini, beberapa lembar kerja anak, serta hasil dari wawancara yang dilakukan oleh salah satu guru kelas di TK Sejahtera Penengahan.

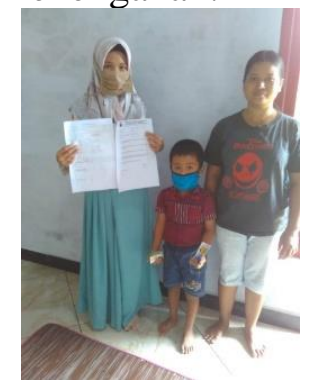

Gambar.1 Pembelajaran

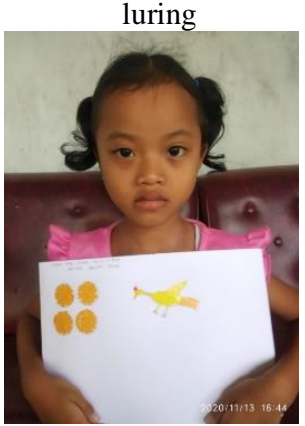

Gambar.3 Hasil karya yang dikirimkan pada pendidik (via WA)

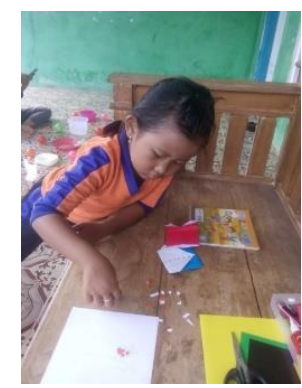

Gambar.2 Proses pembelajaran luring

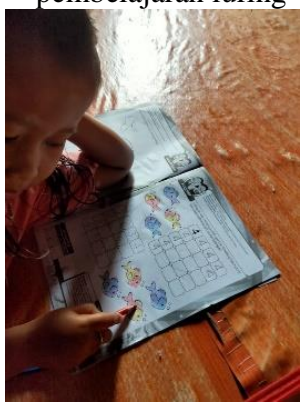

Gambar.4 Proses pembelajaran daring

Dari hasil pengamatan juga, penulis mendapatkan dokumen penting mengenai RPPM yang digunakan selama Covid-19 ini. Dikarenakan pembelajaran dan penilaian yang dilakukan dimasa Covid19 menggunakan daring dan juga luring, maka sekolah memutuskan untuk tidak menggunakan RPPH melainkan hanya menyediakan RPPM sebagai acuan pembelajaran di era pandemi Covid-19 ini. Berikut adalah contoh RPPM yang digunakan di TK Sejahtera Penengahan saat pembelajaran di era pandemi Covid19:

Nama Guru : Dian Resti Ningsih, S.Pd Lembaga : TK Sejahtera Penengahan Alamat : Jalan Partodimejo, Dusun Sidorejo, Desa Klaten

Pemberitahuan kepada wali murid untuk kegiatan Belajar Dari Rumah (BDR).

Assalamualaikum Wr. Wb.

Ayah/ Bunda...

Tema permainan 14 minggu kami di rumah adalah "Tanaman" dengan teks "Tanaman Berbunga". Kami berharap

melalui tema dan kegiatan bermain berikut ini Anda akan mencapai enam bidang pembangunan: (1) Memandang tanaman ciptaan Tuhan. (2) Mengembang kan gerakan, keterampilan motorik lengkap dan halus. (3) Mengelompokkan Nomor. (4) Keaksaraan awal. (5) Berani mengungkapkan ide. (6) Menunjukkan kerajinan tangan. Kegiatan minggu ini:

Senin :

1. Membaca Basmallah sebelum memulai kegiatan (Video)

2. Aku bisa membaca do'a ketika melihat tanaman berbuah (Video)

\section{Selasa :}

1. Aku bisa menanam bunga (Foto)

2. Mencuci tangan dengan sabun (Foto)

Rabu :

1. Asyiknya menyiram bunga bersama ibu (Foto)

2. Yuk mewarnai bunga matahari majalah tanaman halaman 12 (Foto)

\section{Kamis :}

1. Aku bisa menyebutkan macammacam bunga (Video)

2. Aku bisa menyusun batu membentuk huruf B (Foto)

\section{Jum'at :}

1. Bercerita tentang bunga (Video)

2. Membersihkan taman (Foto)

Ayah/ Bunda bisa membimbing kegiatan untuk satu hari. Bila ananda tidak tertarik dengan kegiatan yang kita tawarkan maka Ayah/ Bunda dapat memberikan dorongan dan semangat mereka dahulu, Namun, jika ia menginginkan aktivitas lain, ikuti minatnya sehingga jika menekuni aktivitas yang diinginkan, belajar bermain di rumah itu menyenangkan.

Tolong diamati, difoto, atau diVideo kegiatan, ambil foto atau video dia melakukan aktivitas biasa dan memuja nya, lalu posting video kemajuan grup. Terima kasih....

Wassalamualaikum Wr. Wb. 
Berikut adalah salah satu contoh RPPM TK Sejahtera Penengahan. Setelah melihat RPPM yang digunakan oleh TK Sejahtera Penengahan, berikut ini akan dilampirkan juga format mingguan hasil belajar anak usia dini.

\begin{tabular}{|c|l|c|c|c|}
\hline Lp & $\begin{array}{l}\text { Kompetensi dan } \\
\text { indikator }\end{array}$ & Vka & Hk & Ha \\
\hline NAM & $\begin{array}{l}\text { 1.1-1.2 Merawat } \\
\text { tanaman ciptaan } \\
\text { Tuhan }\end{array}$ & & & \\
\hline F.M & $\begin{array}{l}3.3-4.3 \text { Gerakan } \\
\text { untuk } \\
\text { pengembangan } \\
\text { motorik kasar } \\
\text { dan halus }\end{array}$ & & & \\
\hline KOG & $\begin{array}{l}\text { 3.6-4.6 } \\
\text { Pengelompokkan } \\
\text { bilangan }\end{array}$ & & & \\
\hline BHS & $\begin{array}{l}\text { 3.11-4.11 } \\
\text { Mengetahui } \\
\text { keaksaraan awal }\end{array}$ & & & \\
\hline S.E & $\begin{array}{l}\text { 2.5 Berani } \\
\text { mengungkapkan } \\
\text { sebuah pendapat }\end{array}$ & & & \\
\hline Seni & $\begin{array}{l}\text { 3.15-4.15 } \\
\text { Ekspresi seni } \\
\text { musik \& seni } \\
\text { kriya }\end{array}$ & & & \\
\hline
\end{tabular}

Keterangan:

Vka : Video kegiatan anak

Hk : Hasil Karya

Ha : Hasil akhir

\section{KESIMPULAN}

Dampak dari penyebaran wabah terhadap sebuah proses belajar bagi pendidik, peserta diidk dan juga wali murid, terutama pada proses pembelajaran dan penilaian peserta didik. Menurut pengamatan tentang Pembelajar an dan Penilaian pada Anak Usia Dini di Era pandemic Covid-19 ini, yang dilakukan oleh TK Sejahtera Penengahan adalah dengan cara daring dan luring. Dimana, anak memiliki jadwal untuk daring dan juga luring di setiap harinya. Alasannya yaitu agar proses pembelajaran tidak terlalu monoton, anak tidak bosan karena harus terus menurus belajar dirumah jika hanya dengan wali yang mendampinginya saat belajar, serta dipilihnya daring dan luring ini agar guru dapat melihat dan mendampingi proses belajar anak juga, walaupun tidak setiap hari, melainkan terjadwal yang tentunya sudah disepakati pula oleh orang tua wali murid. Sedangkan, dalam memberikan penilaian, guru bisa mendapatkannya melalui video dan foto proses pembelajaran dan hasil pembelajaran anak yang dikirim melalui whatsapp saat jadwal pembelajaran daring serta dapat mendampingi dan melihat penilaian nya saat luring pula.

\section{DAFTAR PUSTAKA}

Agustin, M., Djoehaeni, H., \& Dwi Puspita, R. (2020). Observational Analysis of Violence On Children and the Implications for Parenting Program Development. Pacific Early Childhood Education Research Association, 14(2), 195$214 . \quad$ doi: https://doi.org/10.17206/apjrece.20 20.14.2.195

Agustin, M. (2011). Permasalahan belajar dan inovasi pembelajaran. Bandung: Refika Aditama.

Arifin, Z. (2016). Evaluasi Pembelajaran (Prinsip, Teknik dan prosedur). Bandung: PT. Remaja Rosdakarya.

Arikunto, S. (1998). Prosedur penelitian Suatu Pendekatan Praktis. Jakarta: Rineka Cipta.

Burhan, B. (2015). Metodologi Penelitian Kualitatif. Jakarta: Rajawali Pers.

Ernofalina, E. (2017). Culture Shocks Experienced by Indonesian Students Studying Overseas. International Journal of Educational Best Practices, 1(2), $87 . \quad$ doi: https://doi.org/10.31258/ijebp.v1n2 .p87-105

Gore, J., Lloyd, A., Smith, M., Bowe, J., Ellis, H., \& Lubans, D. (2017). Effects of professional development on the quality of teaching: Results 
from a randomised controlled trial of Quality Teaching Rounds. Teaching and Teacher Education, 68, 99-113. doi: 10.1016/j.tate.2017.08.007

Hasanah, H. (2017). TEKNIK-TEKNIK OBSERVASI (Sebuah Alternatif Metode Pengumpulan Data Kualitatif Ilmu-ilmu Sosial). AtTaqaddum, $\quad 8(1), \quad 21 . \quad$ doi: 10.21580/at.v8i1.1163

Khan, A., Khan, S., Zia-Ul-Islam, S., \& Khan, M. (2017). Communication Skills of a Teacher and Its Role in the Development of the Students' Academic Success. Journal of Education and Practice, 8(1), 1821. Diambil dari http://www.communicationskillswo rld.com/communicationskillsfortea chers.html\%0Awww.iiste.org

Maiza, Z., \& Nurhafizah, N. (2019). Pengembangan Keprofesian Berkelanjutan dalam Meningkatkan Profesionalisme Guru Pendidikan Anak Usia Dini. Jurnal Obsesi: Jurnal Pendidikan Anak Usia Dini, 3(2), $356 . \quad$ doi: 10.31004/obsesi.v3i2.196

Mendikbud. (2014). Peraturan Menteri Pendidikan dan Kebudayaan Republik Indonesia Nomor 146 tahun 2014 tentang Kurikulum 2013 Pendidikan Anak Usia Dini.

Mukaromah, L. (2019). Implementasi Asesmen Perkembangan Karakter Anak Usia Dini di TK Green School Jogja.

Mulyasa. (2012). Manajemen PAUD. Bandung: PT. Remaja Rosdakarya.

Nana, S. (2009). Penilaian Hasil Proses Belajar Mengajar. Bandung: PT. Remaja Rosdakarya.

Nicoleta, D. (2010). The relationship between candidate teacher's communication skills and their attitudes towards teaching profession. Procedia - Social and Behavioral Sciences, 9, 919-922. doi: 10.1016/j.sbspro.2010.12.259
Oktarina, A., Angraini, W., \& Susilawati, B. (2020). Penggunaan Media Kolase Dalam Mengembangkan Keterampilan Motorik Halus Anak Usia 5-6 Tahun. 3(2), 186-198. doi: https://doi.org/10.24042/ajipaud.v3 i2 2.7408

Oktarina, A., \& Suryadilaga, M. A. (2020). Pendidikan Seks Usia Dini Dalam kajian Hadis. Jurnal Riwayah: IAIIN Kudus, 6(2), 6. doi: http://dx.doi.org/10.21043/riwayah. v6i2.7615.

Oktarina, A., \& Maemonah. (2019). Filsafat Pendidikan Maria Montessori Dengan Pendidikan Aud. Jurnal UIN Jogyakarta, VI(2), 64-88. Diambil dari https://jurnal.ar-

raniry.ac.id/index.php/bunayya/arti cle/view/7277

Paizaluddin, E. (2016). Penelitian Tindakan Kelas (Classroom Action Research). Bandung: Alfabeta.

Panjaitan, N. Q., Yetti, E., \& Nurani, Y. (2020). Pengaruh Media Pembelajaran Digital Animasi dan Kepercayaan Diri terhadap Hasil Belajar Pendidikan Agama Islam Anak. Jurnal Obsesi: Jurnal Pendidikan Anak Usia Dini, 4(2), 588. doi: 10.31004/obsesi.v4i2.404

Pramudiana, I. D., \& Setyorini, T. D. (2019). Hubungan Antara Gegar Budaya Dengan Penyesuaian Sosial Siswa Papua di Magelang. Praxis, 1(2), $125 . \quad$ doi: https://doi.org/10.24167/praxis.v1i 2.1631

Purwanto. (2020). Dampak Pandemi Covid-19 terhadap Proses Pengajaran bagi Guru dan Siswa Pendahuluan. Jurnal Studi Guru dan Pembelajaran, 3(2), 289-295.

Rohita. (2020). The Ability of Ece Teachers To Use ICT in The Industrial Abstrak. Jurnal Obsesi : Jurnal Pendidikan Anak Usia Dini, 4(2), 502-511. doi: 10.31004/obsesi.v4i1.339 
Ronkainen, R., Kuusisto, E., \& Tirri, K. (2019). Growth mindset in teaching: A case study of a Finnish elementary school teacher. International Journal of Learning, Teaching and Educational Research, 18(8), 141-154. doi: 10.26803/ijlter.18.8.9

Samatowa, U., R. A. S. (2019). Metode Pembelajaran Sains Untuk Anak Usia Dini. Tira Smart.

Setyosari, P. (2017). Menciptakan Pembelajaran Yang Efektif Dan Berkualitas. JINOTEP (Jurnal Inovasi dan Teknologi Pembelajaran) Kajian dan Riset dalam Teknologi Pembelajaran, 1(5), 20-30. doi: 10.17977/um031v1i12014p020

Sisca, R. (2007). Pembelajaran Untuk PAUD. 3(September), 1-8. Diambil dari i.\%0Awww.isjoni.net/web/content/ view/44/4/-44k-Tembolok-Laman sejenis: 17 Oktober 2007

Sutrisno, H. (2000). Metodologi Research. Yogyakarta: Andi.

Syah, R. H. (2020). Dampak Covid-19 pada Pendidikan di Indonesia: Sekolah, Keterampilan, dan Proses Pembelajaran. SALAM: Jurnal Sosial dan Budaya Syar-i, 7(5). doi: 10.15408/sjsbs.v7i5.15314

Wahyudin, U. (2010). Penilaian Perkembangan Anak Usia Dini. Bandung: CV. Falah Production.

Zalyana. (2016). Konsep Pembelajaran pada Anak Usia Dini. Pekanbaru: Cahaya Firdaus. 